\title{
Nanoscopic Strength Analysis of Work-Hardened L-Grade Austenitic Stainless Steel, 316(NG)*
}

\author{
Nobuo Nagashima ${ }^{1}$ and Saburo Matsuoka ${ }^{2}$ \\ ${ }^{1}$ National Institute for Materials Science (NIMS), Tukuba 305-0047 \\ ${ }^{2}$ Graduate School of Engineering, Kyushu University, Fukuoka 819-0395
}

\begin{abstract}
Stress corrosion cracking (SCC) occurs in shrouds and piping of L-grade austenitic stainless steels at nuclear power plants. A workhardened layer, where the transgranular SCC initiates, is considered to be one of the probable cause for this occurrence. In order to clarify the microstrucural characteristics of work-hardened layer at the surface of shrouds or piping, the strengthen analysis of L-grade austenitic stainless steel, 316(NG), rolled at the reduction in area, $R A$, of 10, 20, 30, 40 and 50\% at room temperature were conducted on a nanoscopic scale, using an ultra-microhardness tester, TEM and SEM. TEM and SEM observation showed that the microstructural parameters are the dislocation cell size, $d_{c e l}$, coarse slip spacing, $l_{c s l}$, and austenitic grain size, $d_{\gamma}$. Referring $10 d_{c e l}$ and $10 l_{c s l}$, Vickers hardness, $H v$, corresponding to macro strength was expressed as $H v=H v^{*}{ }_{\text {bas }}+H v^{*}{ }_{\text {sol }}+H v^{*}{ }_{\text {dis }}+H v^{*}{ }_{c e l}+H v^{*}{ }_{c s l} . H v^{*}$ bas $(=100)$ is the base hardness, $H v^{*}$ sol is the solid solution strengthening hardness, $H v^{*}{ }_{d i s}$ is the dislocation strengthening hardness in the dislocation cell, and $H v^{*}{ }_{c e l}$ and $H v^{*}{ }_{c s l}$ are the fine grain strengthening hardness due to the dislocation cell and coarse slip. $H v^{*}{ }_{\text {sol }}$ was about 50 , independently of $R A$. $H v^{*}$ dis was zero at $R A<30 \%$ and increased at $R A>30 \%$. $H v^{*}{ }_{c e l}$ and $H v^{*}{ }_{c s l}$ increased with increasing in $R A$ and were kept constant at about 50 and 120 at $R A=20$ and $30 \%$, respectively. It was suggested from these results that all dislocations introduced by rolling might be dissipated for the creation of dislocation cells and coarse slips at $R A<30 \%$ and that the microstructure contributing to the fine grain strengthening due to the dislocation cell and coarse slip might be accomplished at $R A=30 \%$. The dislocation strengthening in the dislocation cell might begin to operate at $R A>30 \%$. [doi: $10.2320 /$ matertrans.47.2326]
\end{abstract}

(Received May 25, 2006; Accepted July 31, 2006; Published September 15, 2006)

Keywords: BWR(Boiling Water Reactor), SCC(Stress Corrosion Cracking), L-grade austenitic stainless steel, 316(NG), work hardening, nanoindentation, microstructural parameters

\section{Introduction}

Since the 1970's, there have been many cracking incidences in boiling water reactors (BWR) pressure boundary components, such as primary loop re-circulation (PLR) pipes made with stainless steels. The cracks grew along heataffected zones, and their fractrographic features were characterized by intergranular stress corrosion cracking (IGSCC). The cracking was caused by typical weld sensitization in heat affected zones due to $\mathrm{Cr}$ depletion along grain boundaries. ${ }^{1)}$ L-grade austenitic stainless steel was developed to control the formation of $\mathrm{Cr}$ carbides. ${ }^{1)}$ However, recently, SCC has been observed in L-grade austenitic stainless steel in core shrouds and PLR pipes in Japanese BWR plants. ${ }^{2)}$ An investigation of samples taken from the nuclear power plants showed that the cracking originated in the surface unit of the material, and that transgranular stress corrosion cracking (TGSCC) had occurred. TGSCC occurred in a surface heavily cold worked by machining and in an area highly strained by weld deformation. This SCC mechanism has not been fully explained.

The authors have developed ultra micro-hardness tester on the basis of an atomic force microscope (AFM). ${ }^{3)}$ We have also developed an empirical equation for converting an indentation force-penetration depth $(\mathrm{F}-\mathrm{h})$ curve to the Vickers hardness, $H v^{*}$, by using a single metal crystal as a reference sample. ${ }^{4,5)}$ This makes it possible to obtain hardness profiles in regions ranging in size from the nano scale to the macro scale by correlating the hardness obtained by using the tester and the empirical equation with the macroscopic

*This Paper was Originally Published in Japanese in J. Japan Inst. Metals 69 (2005) 472-480. hardness obtained by Vickers hardness testing. We have also made it possible to separate the various strengthening factors associated with solution, dislocation, particle dispersion, and grain boundaries (fine grain) by determining structural parameters from AFM structural observations and by correlating a hardness profile with these structural parameters. We named this set of processes "nano-meso-macro strength analysis"6) and applied the technique to the analysis of the strength mechanism of steels, such as $1-\mu \mathrm{m}$ ultra-finegrain ferrite steel, ${ }^{5)}$ Low carbon ferrite-bainite steel, ${ }^{7)}$ ferrite-pearlitic steel, ${ }^{8)}$ and tempered martensitic steel. ${ }^{9)}$

In this study, we performed a nano-meso-macro strength analysis on cold-rolled L-grade austenitic stainless steel SUS316 (NG) as part of an investigation of the causes of TGSCC in the work-hardened layer of shrouds and PLR pipes. We also compared the results of our analysis with those of a previous investigation on the occurrence of SCC in cold-rolled austenitic stainless steel.

\section{Experimental Method}

\subsection{Material information}

The test material used was L-grade austenitic stainless steel SUS316 (NG), whose chemical composition is shown in Table 1. Nitrogen $(0.109$ mass $\%)$ is added to the material to compensate for the reduction in strength caused by the Lgrade content. The steel was cold rolled at room temperature

Table 1 Chemical composition of SUS316(NG) steel (mass \%).

\begin{tabular}{ccccccccc}
\hline $\mathrm{C}$ & $\mathrm{Si}$ & $\mathrm{Mn}$ & $\mathrm{P}$ & $\mathrm{S}$ & $\mathrm{Ni}$ & $\mathrm{Cr}$ & $\mathrm{Mo}$ & $\mathrm{N}$ \\
\hline 0.007 & 0.28 & 1.49 & 0.033 & 0.005 & 12.23 & 16.58 & 2.07 & 0.109
\end{tabular}




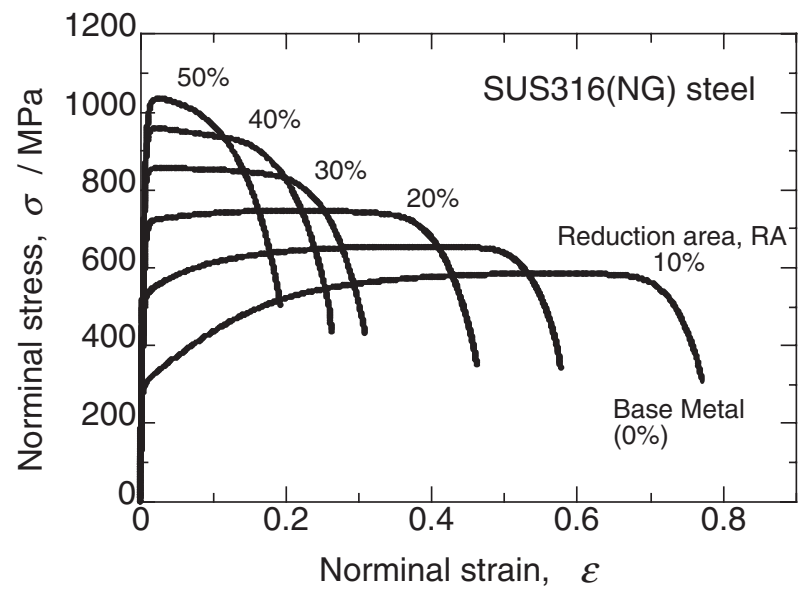

Fig. 1 Nominal stress-strain curves of rolled SUS316(NG) steels. ${ }^{10)}$

Table 2 Tensile properties of rolled SUS316(NG) steels. ${ }^{10)}$

\begin{tabular}{|c|c|c|c|c|c|c|c|}
\hline \multicolumn{2}{|c|}{ Rolling at $\sim 25^{\circ} \mathrm{C}$} & \multirow{2}{*}{$\begin{array}{c}\sigma_{0.2} \\
(\mathrm{MPa})\end{array}$} & \multirow{2}{*}{$\begin{array}{c}\sigma_{\mathrm{B}} \\
(\mathrm{MPa})\end{array}$} & \multirow{2}{*}{$\begin{array}{c}\delta_{\mathrm{U}} \\
(\%)\end{array}$} & \multirow{2}{*}{$\begin{array}{c}\delta_{\mathrm{T}} \\
(\%)\end{array}$} & \multirow{2}{*}{$\begin{array}{c}\phi \\
(\%)\end{array}$} & \multirow[b]{2}{*}{ HV } \\
\hline $\begin{array}{c}\text { Reduction } \\
\text { area, RA (\%) }\end{array}$ & $\begin{array}{l}\text { True } \\
\text { Strain }\end{array}$ & & & & & & \\
\hline 0 & 0 & 285 & 589 & 55.7 & 78.2 & 83.7 & 144 \\
\hline 10 & 0.104 & 508 & 659 & 37.9 & 57.6 & 82.1 & 226 \\
\hline 20 & 0.223 & 651 & 751 & 19.9 & 44.1 & 82.3 & 278 \\
\hline 30 & 0.358 & 773 & 858 & 2.2 & 29.9 & 80.8 & 314 \\
\hline 40 & 0.513 & 846 & 968 & 1.6 & 22.5 & 78.6 & 341 \\
\hline 50 & 0.693 & 907 & 1041 & 1.6 & 17.4 & 76.4 & 358 \\
\hline
\end{tabular}

to give a reduction in area $\left(R A=\left(A_{0}-A\right) / A_{0}\right)$ of $10,20,30$, 40 , or $50 \%$; each cold-rolled sheet had thickness of $10 \mathrm{~mm}$ and a width of $40 \mathrm{~mm}$. Figure 1 shows the stress-strain curve obtained for each rolled steel. ${ }^{10)}$ Table 2 shows the mechanical properties, $0.2 \%$ yield strength $\left(\sigma_{0.2}\right)$, tensile strength $\left(\sigma_{\mathrm{B}}\right)$, uniform elongation $\left(\delta_{\mathrm{U}}\right)$, total elongation $\left(\delta_{\mathrm{T}}\right)$, and reduction in area $(\varphi)$. The table also shows the Vickers hardness (HV) measured with an applied indentation force of 196.1 N. The Vickers hardness of the base metal was 144, whereas that of steel with a reduction in area of $50 \%$ reached 356.

\subsection{Structure observation method}

The structure of cold-rolled specimens was observed by field emission scanning electron microscopy (FE-SEM) at an acceleration voltage of $20 \mathrm{kV}$. In addition, a field emission transmission electron microscopy (FE-TEM) observation was carried out at an acceleration voltage of $300 \mathrm{kV}$ to investigate the details of the slip bands and dislocation cells induced by cold rolling. The FE-SEM observation was carried out on a cross section (Face C) of the specimen perpendicular to the rolling direction.

Samples for SEM were first ground using emery papers of various grinds from 230 to 600 grit and then etched in a solution of $20 \mathrm{vol} \%$ of $\mathrm{HNO}_{3}, 60 \mathrm{vol} \% \mathrm{HCl}$ and $20 \mathrm{vol} \%$ of $\mathrm{H}_{2} \mathrm{O}$ at $293 \mathrm{~K}$. Samples for TEM obtained from thin slices with $0.3 \mathrm{~mm}$ thickness were firstly mechanically thinned to $30 \mu \mathrm{m}$ and then electrolytically polished in a solution containing 5 vol\% perchloric acid and 95 vol\% acetic acid, using a twin jet apparatus at a potential of $20 \mathrm{~V}$ and a temperature of $298 \mathrm{~K}$.

\subsection{Hardness measurement method}

In hardness measurement, an ultra micro-hardness tester (indentation force: 0.1 to $5 \mathrm{mN}$ ), a micro-hardness tester ( 1 to $2000 \mathrm{mN}$ ), and a Vickers hardness tester (0.196 to $490 \mathrm{~N})$ were used to investigate the dependence of the hardness on the indent size over the nano-, meso-, and the macro-sized regions, respectively. The hardness values obtained by using the three hardness testers are called to as the nano hardness, the meso hardness, and the macro hardness, respectively. Hardness measurements were made on Face $\mathrm{C}$, as in the structural observation. The samples, cut to a thickness of $2 \mathrm{~mm}$, were buffed and then electrolytically polished in a solution of $8 \mathrm{vol} \%$ perchloric acid, $10 \mathrm{vol} \%$ 2-butoxyethanol, $70 \mathrm{vol} \%$ ethanol, and $12 \mathrm{vol} \%$ distilled water, at a potential of $40 \mathrm{~V}$ and a temperature of $273 \mathrm{~K}$. Electropolishing of the surfaces was intended to remove work-hardened layers formed during the processes from cold rolling through buffing. The ultra micro-hardness test was carried out by using the AFM ultra micro-hardness tester with special levers developed by the authors. ${ }^{4)}$ Two types of special levers were used that had triangular pyramidal diamond indenters with apical angles of 60 and $115^{\circ}$, respectively, in the lever center. The lever with the triangular pyramidal indenter with an apical angle of $60^{\circ}$ is referred to as lever No. 1 and the one with an apical angle of $115^{\circ}$ as lever No. 2. The microhardness test was carried out by using a Shimazu DUH201 instrument with a triangular pyramidal indenter with an apical angle of $115^{\circ}$. An Akashi micro Vickers hardness tester was used for the Vickers hardness test. The diamond indenter was of a quadrangular pyramidal shape with a face angle of $136^{\circ}$.

According to the definition of the Vickers hardness, the hardness calculated by dividing the indentation force by the surface area of the indent. In the ultra micro-hardness test, this hardness calculated shows a size effect in which the hardness increases with decreasing indentation depth. ${ }^{11)}$ It is suggested that this size effect occurs because the radius of the indenter tip has an effect that appears as a result of the shallow indentation depth. ${ }^{11)}$ To eliminate this effect, we have proposed the following empirical equation to convert indentation force-depth (F-h) curves (see Fig. 7) obtained in ultra micro-hardness tests to the Vickers hardness $H v^{*}$, using several electrolytically polished single metal crystals as reference specimens. ${ }^{4,5)}$

$$
H v^{*}=\left\{\frac{F}{p(h+q)^{2}}\right\}^{n}
$$

where $p, q$, and $n$ are constants and need to be specified for each indenter. This approach can be applied to F-h curves (see Fig. 8) obtained in a micro-hardness test. ${ }^{8}$ ) Table 3 shows $p, q$, and $n$ values for each of the pyramidal indenters.

\section{Experimental Results}

\subsection{Structural observation}

Figure 2 shows an SEM image of the microstructure of the SUS316 (NG) base metal (i.e., a sample with a reduction in 
Table 3 Constants $p, q$ and $n$ in an experimental equation, $H v=$ $\left\{F /\left[p(h+q)^{2}\right]\right\}^{n}$

\begin{tabular}{ccccc}
\hline Hardness tester & Indenter & $p$ & $q$ & $n$ \\
\hline \multirow{2}{*}{ Nano-micro } & $60^{\circ}$ indenter, No. 1 lever & $9.011 \times 10^{-5}$ & 66.6 & 1.262 \\
\cline { 2 - 5 } & $115^{\circ}$ indenter, No. 2 lever & $6.886 \times 10^{-4}$ & 49.51 & 1.151 \\
\hline Micro & $115^{\circ}$ indenter & $5.530 \times 10^{-7}$ & 255.2 & 1.175 \\
\hline
\end{tabular}

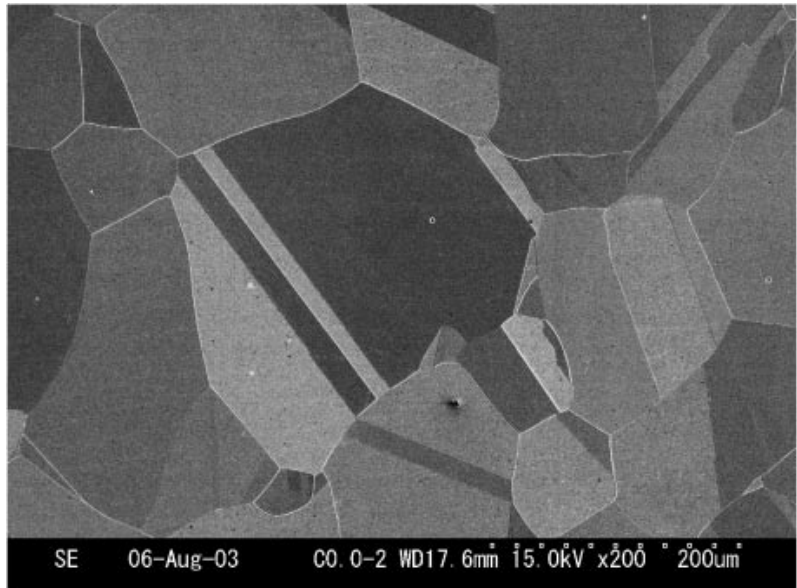

Fig. 2 SEM image of microstructure in parent SUS316(NG) steel.
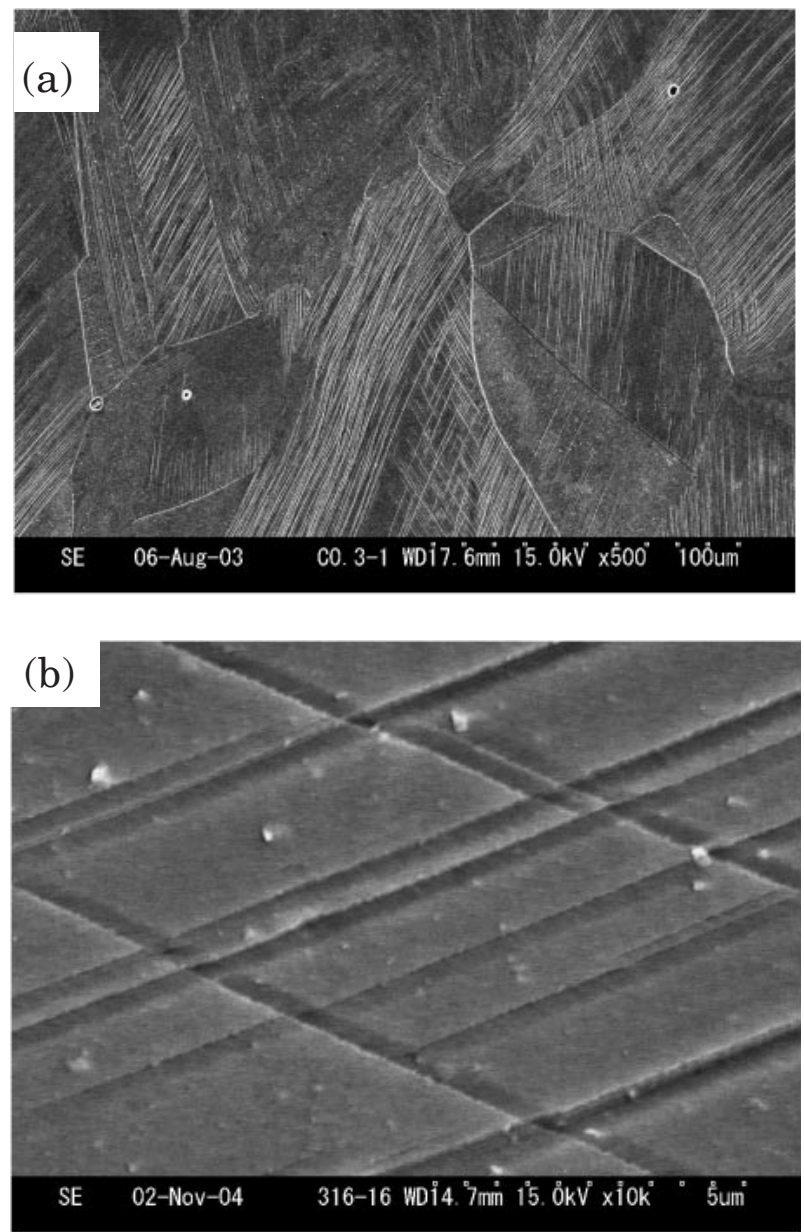

Fig. 3 SEM images of microstructure in 30\% rolled SUS316(NG) steel (a) Low magnification (b) High magnification.
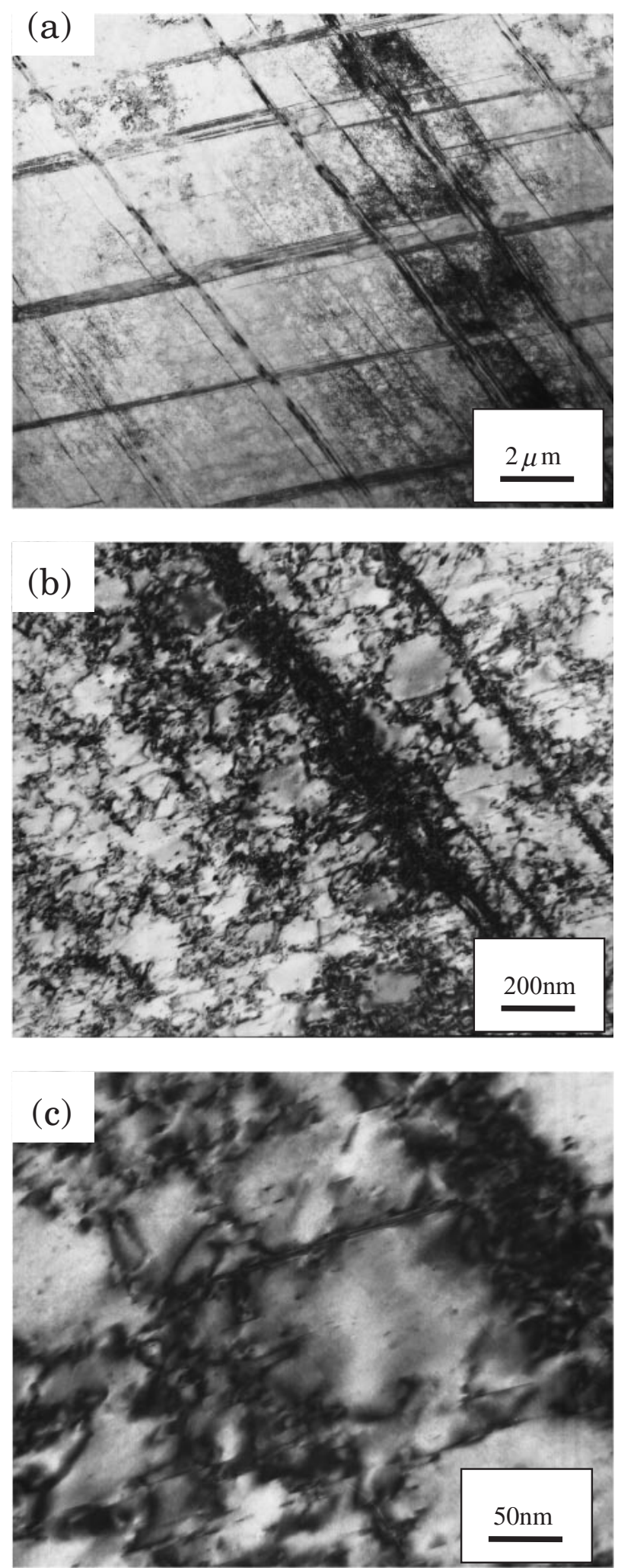

Fig. 4 TEM images of $30 \%$ rolled SUS316(NG) steel. (a) Low magnification (b) Medium magnification (c) High magnification.

area of $0 \%$ ). The SEM image shows that the austenitic grain size is about $150 \mu \mathrm{m}$.

Figures 3 and 4 show SEM and TEM images of the microstructure of a sample with a reduction in area of $30 \%$, it's a typical example for cold-rolled SUS316 (NG) steel. Figure 5 shows the slip deformation model ${ }^{12)}$ observed on the 


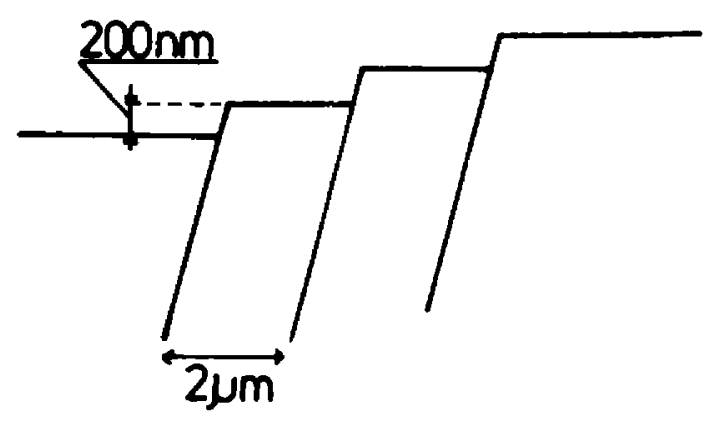

\section{(a) $\varepsilon<10 \%$}
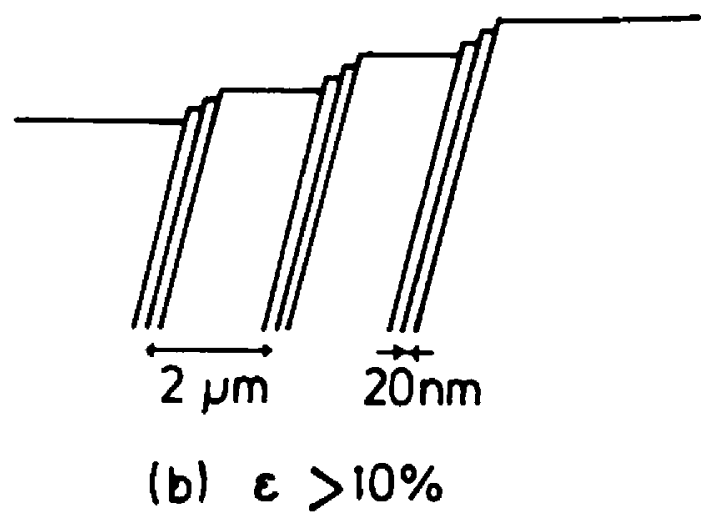

Fig. 5 Slip deformation model. ${ }^{12)}$

surface of aluminum, which has the same face-centered cubic structure as SUS316 (NG) steel.

Figure 5 shows that large slip lines with a height difference of $200 \mathrm{~nm}$ are formed at a strain $\varepsilon$ of less than $10 \%$. As the strain increases, the spacing between the large slip lines decreases and saturates at a spacing of $2 \mu \mathrm{m}$ at a strain of $10 \%$. As the strain increases beyond $10 \%, 20 \mathrm{~nm}$-spaced fine slip lines are formed in the root of the $2 \mu \mathrm{m}$-spaced slip lines. As shown by the SEM image in Fig. 3 and the TEM image in Fig. 4(a), $2 \mu \mathrm{m}$-spaced large slip lines are also formed in the SUS316 (NG) specimen with a reduction in area of 30\% (a true strain of $35.8 \%$ ). In addition, the TEM image in Fig. 4(b) shows that $20 \mathrm{~nm}$-spaced fine slip lines are formed in the root of the $2 \mu \mathrm{m}$-spaced slip lines.

The TEM images in Figs. 4(b) and 4(c) show the formation of dislocation cells (subgrains). Fig. 6 shows the relationship between the dislocation cell size and the reduction in area. In each rolled specimen, five dislocation cells were randomly selected, and their average size was used as the dislocation cell size. Figure 6 also shows the tensile-test results for lowalloy steel obtained by Bassim et al. ${ }^{13)}$ They cut a fractured tensile-test specimen at several positions in the reduction area, and performed TEM observations of the cross-section of each sample cut. They then calculated the reduction in area by using the diameter of each sample and the initial diameter of the test specimen. This showed that the dislocation cell size decreases with increasing reduction in area and becomes constant at a spacing of nearly $0.4 \mu \mathrm{m}$ for a reduction in area of more than $20 \%$. In comparison with this result, the dislocation cell size in the cold-rolled SUS316 (NG) steel is

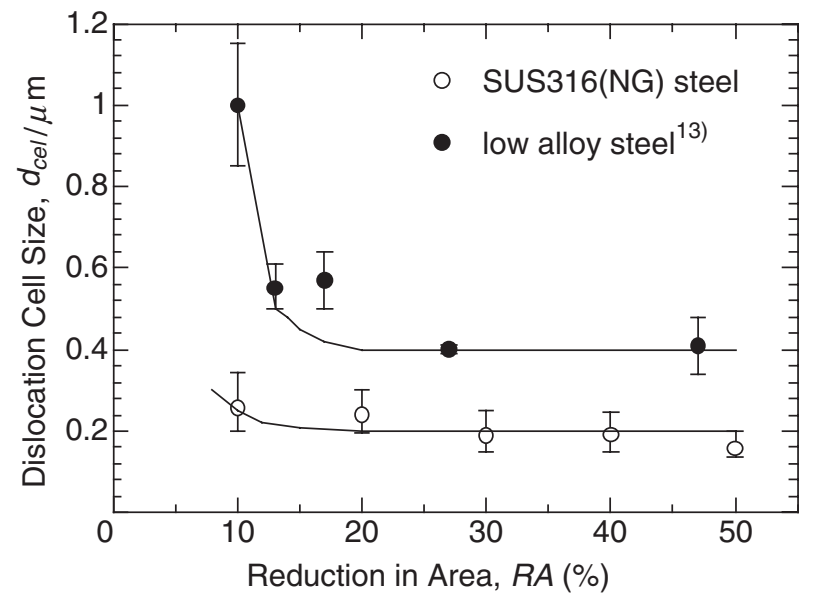

Fig. 6 Relationships between dislocation cell size and reduction in area for rolled SUS316(NG) steels.

as small as 0.15 to $0.25 \mu \mathrm{m}$, and the reduction in area giving a constant dislocation cell size is estimated to be 10 to $20 \%$.

As mentioned in the introduction, structural parameters play an important role in the nano-meso-macro strength analysis. ${ }^{5-9)}$ On the basis of the above results, the structural parameters of cold-rolled SUS316 (NG) steel are an austenitic grain size of $150 \mu \mathrm{m}$, slip spacings of $2 \mu \mathrm{m}$ and $20 \mathrm{~nm}$, and dislocation cell sizes of 0.15 to $0.25 \mu \mathrm{m}$.

\subsection{Hardness measurement}

Figure 7 shows typical F-h curves obtained using the AFM ultra micro-hardness tester. In order to show the results clearly, F-h curves for the base metal and for specimens with reductions in area of 10,30, and 50\% are shown in Fig. 7(a), and those for the base metal and specimens with reductions in area of 20 and $40 \%$ are shown in Fig 7(b). In the F-h curves, if the indentation force is the same, the material is harder for shallower indentation depths. Therefore, the results of hardness measurement in the nano region in Fig. 7 show that specimens with reductions in area of 10, 20, or 30\% are as hard as the base metal and those with reductions in area of 40 or $50 \%$ are harder than the base metal. As shown in Table 2, the Vickers hardness increases with increasing reduction in area. These results mean that the dependence of the hardness on the reduction in area differs between the nano and the macro regions.

Figure 8 shows typical $\mathrm{F}-\mathrm{h}$ curves obtained by using the micro-hardness tester. A comparison between Fig. 7 and Fig. 8 shows that the maximum indentation force is 500 times larger in the micro-hardness test than in the ultra microhardness test. In the meso-hardness obtained micro-hardness tester, the indentation depth decreases and the hardness increases in proportion to the reduction in area. This tendency agrees with that of the macro-hardness obtained with the micro-Vickers hardness tester (Table 2).

Figure 9 shows the indent size dependency of hardness over the nano-meso-macro regions. Fig. 9(a) shows the results for the base metal and specimens with reductions in area of 10, 30, and 50\%, and Fig. 9(b) shows those for the base metal and specimens with reduction in area of 20 and $40 \%$. The indent size on the horizontal axis is expressed as 

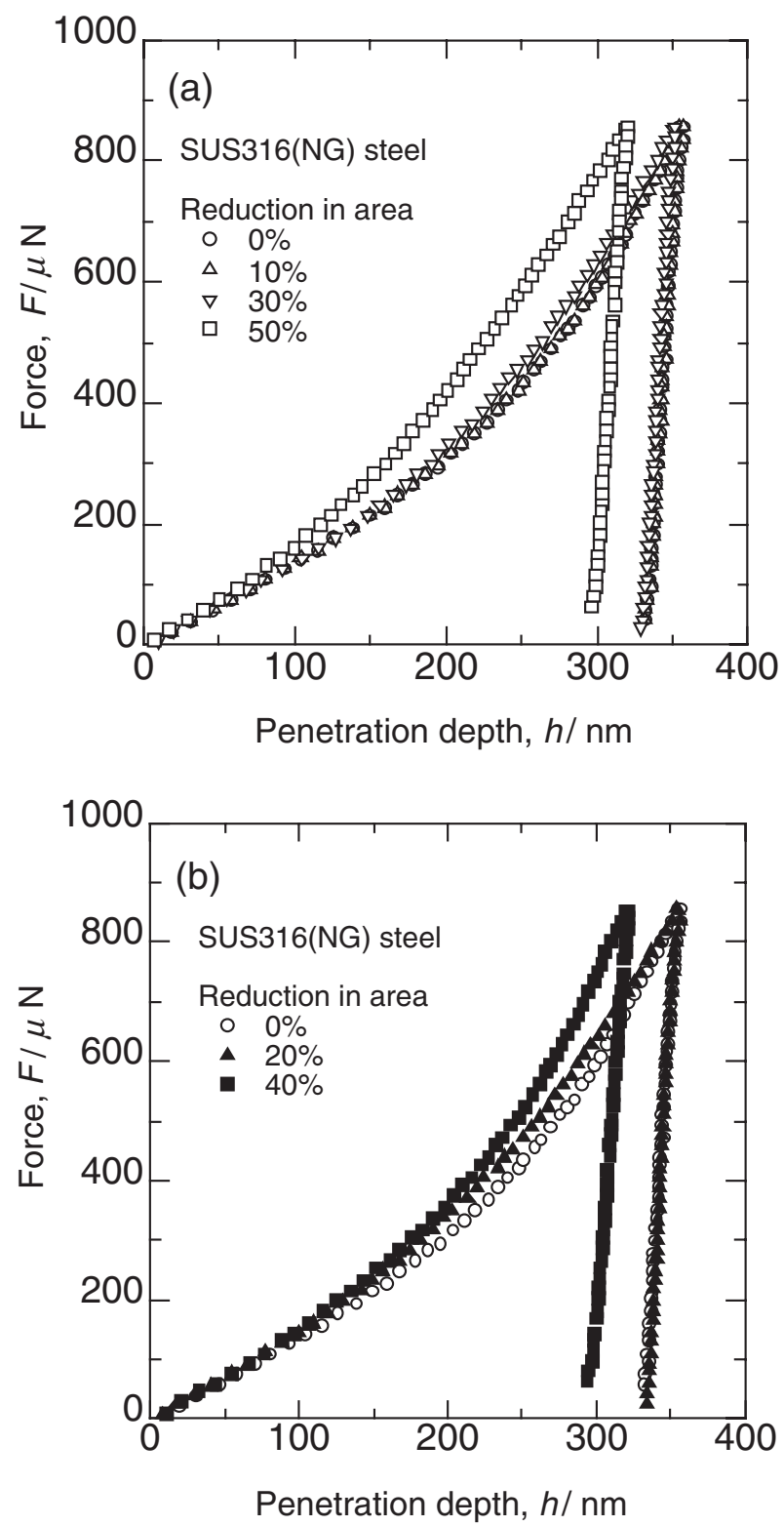

Fig. 7 Force-penetration depth curves obtained by ultra-microhardness tester for parent and rolled SUS316(NG) steels. (a) Reduction in area of 0 , 10,30 and $50 \%$ (b) Reduction in area of 0,20 and $40 \%$.

the square root of the projected area of the indent in order to show test results for indenters of different shapes in a unified manner. The nano-hardness obtained in the ultra microhardness test, the meso-hardness obtained in the microhardness test, and the macro-hardness obtained in the Vickers hardness test are shown for indent sizes smaller than $2 \mu \mathrm{m}, 2-$ $20 \mu \mathrm{m}$, and larger than $20 \mu \mathrm{m}$, respectively. The nanohardness and the meso-hardness were converted to the Vickers hardness by applying eq. (1) to the F-h curves shown in Figs. 7 and 8. The structural parameters in Fig. 9 are the dislocation cell size $d_{c e l}=0.15$ to $0.25 \mu \mathrm{m}, 10 d_{c e l}$, which is 10 times $d_{c e l}$, and $10 l_{c s l}$, which is 10 times the $2-\mu \mathrm{m}$ large slip spacing $l_{c s l} . d_{c e l}$ is averaged at $0.2 \mu \mathrm{m} .10 d_{c e l}$ or $10 l_{c s l}$ shows the position where fine grain strengthening by dislocation cells or slip spacing saturates and the hardness becomes constant. This will be explained in detail in the Discussion section below.
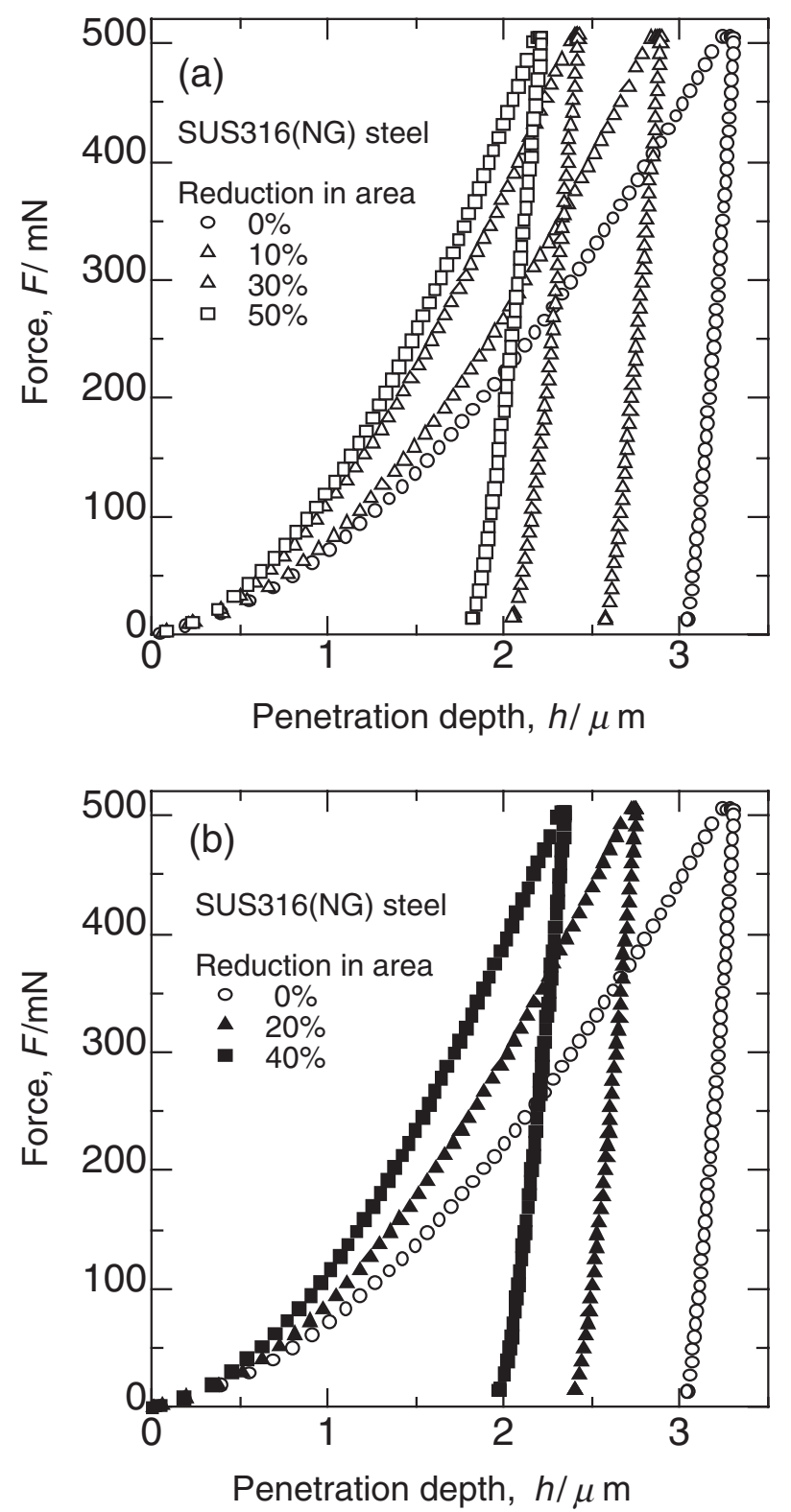

Fig. 8 Force-penetration depth curves obtained by microhardness tester for parent and rolled SUS316(NG) steels. (a) Reduction in area of 0, 10, 30 and $50 \%$ (b) Reduction in area of 0,20 and $40 \%$.

In Fig. 9, the hardness of the base metal is nearly constant over the nano and macro regions, with a value of 150 . The hardness of the cold-rolled specimens with reduction in area of $10-50 \%$ increases with increasing indent size. The hardness appears to change hierarchically in three steps corresponding to $d_{c e l}, 10 d_{c e l}$, and $10 l_{c s l}$. In the nano-hardness region, in the first step, the hardness of the specimens with reductions in area of $10-30 \%$ corresponds to that of the specimen with reduction in area of $0 \%$ (the base metal), whereas the hardness of specimens with reductions in area of 40 and $50 \%$ is greater than that of the base metal. The mesohardness in the second step and the macro-hardness in the third step increase linearly with increasing reduction in area.

\section{Discussion}

The authors first applied the nano-meso-macro strength 

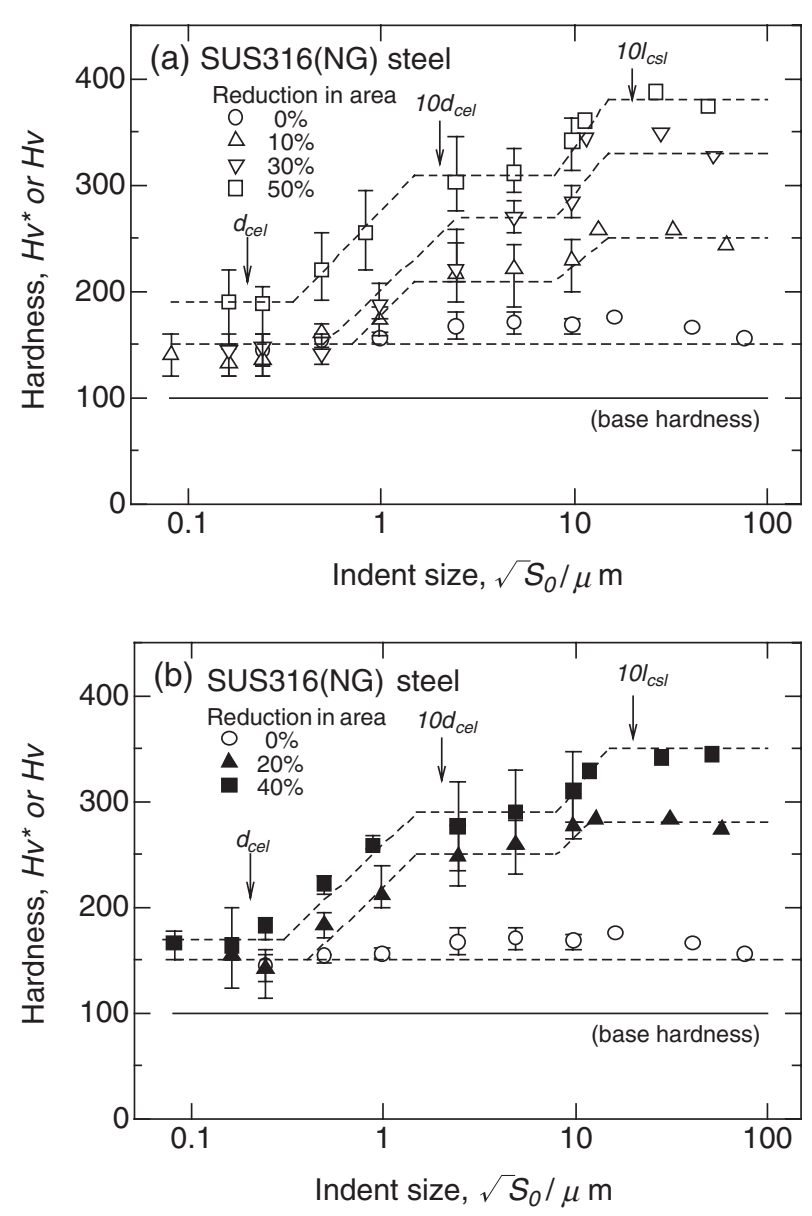

Fig. 9 Relationships between converted hardness or Vickers Hardness and indent size for parent and rolled SUS316(NG) steels. (a) Reduction in area of $0,10,30$ and $50 \%$. (b) Reduction in area of 0,20 and $40 \%$.

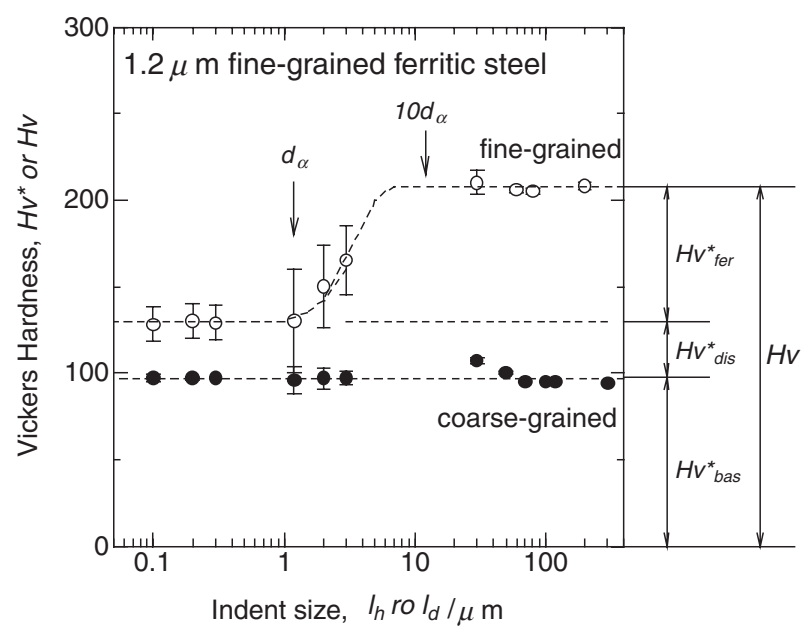

Fig. 10 Relationship between converted hardness or Vickers hardness and indent size for $1.2 \mu \mathrm{m}$ fine-grained ferritic steel. ${ }^{6}$ )

analysis to $1-\mu \mathrm{m}$ ultra fine-grain ferrite steel. ${ }^{6)}$ Figure 10 shows the indent size-dependency of the hardness of $1-\mu \mathrm{m}$ ultra fine-grain ferrite steel and 30- $\mu \mathrm{m}$ large-grain ferrite steel. The side length $l_{h}$ of a triangular indent and the vertical angle length $l_{d}$ of a rectangular indent were used to represent the indent size in the ultra micro-hardness test and in the

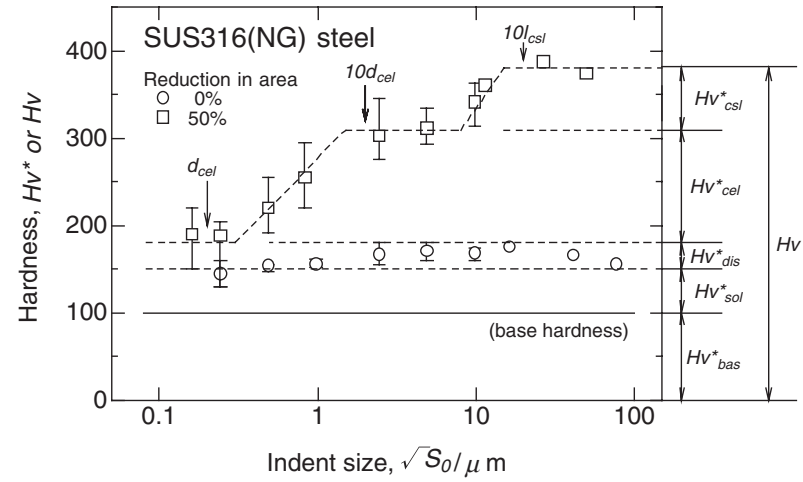

Fig. 11 Relationships between converted hardness or Vickers hardness and indent size for parant and 50\% rolled SUS316(NG) steels.

Vickers hardness test, respectively. The hardness of the large-grain ferrite steel is independent of the indent size and nearly corresponds to the base hardness of iron, which has a value of 100. The hardness of the ultra fine-grain ferrite steel begins to increase near the grain diameter $d_{\alpha}$ and saturates at $10 d_{\alpha}$. It then reaches the macro-hardness obtained in the Vickers hardness test. Miyazaki et al. ${ }^{14)}$ investigated the effect of the ratio of the crystal grain size $d$ to the thickness $B$ on the tensile strength by using plate specimens of $\mathrm{Cu}, \mathrm{Cu}-$ 13 at\% $\mathrm{Al}$, and $\mathrm{Fe}$, and showed that the tensile strength saturates when the thickness is nearly five times the grain size, i.e. $B=5 d$, and coincides with the macro-characteristics. Their results, as well as the finding that a plastic zone twice the indent size is formed around the indent, ${ }^{15)}$ can explain the hardness saturation at $10 d_{\alpha}$ in ultra fine-grain ferrite steel; the results also show that $d_{\alpha}$ and $10 d_{\alpha}$ are important structural parameters. Based on these two structural parameters, the macro-hardness of ultra fine-grain ferrite steel or the Vickers hardness $\mathrm{Hv}$ can be split up into the base hardness $\mathrm{Hv}^{*}$ bas of iron, the solid solution strengthening hardness $\mathrm{Hv}^{*}$ sol, the dislocation strengthening hardness $H v^{*}{ }_{\text {dis }}$, and the fine grain strengthening hardness $\mathrm{Hv}^{*}{ }_{\text {fer }}$.

In particular, the locking parameter $k$ in the following Hall-Petch equation was obtained from the fine grain strengthening hardness $\mathrm{Hv}^{*}$ fer , and the value agreed with that from the tensile test. ${ }^{6}$ )

$$
\sigma=\sigma_{0}+\frac{k}{d_{\alpha}^{1 / 2}}
$$

This analysis was applicable to several tempered martensitic steels with different strengths. ${ }^{9)}$

A figure similar to Fig. 10 was created by using the results for the SUS316 (NG) steel base metal and the specimen with a reduction in area of 50\%. This is shown in Fig. 11. In Fig. 11, the structural parameters are the dislocation cell size $d_{c e l}, 10 d_{c e l}$, which is 10 times $d_{c e l}$, and $10 l_{c s l}$, which is 10 times the large slip spacing $l_{c s l}$.

The Vickers hardness $H v$ of the specimen with a reduction in area of $50 \%$ is split up into the base hardness $H v^{*}$ bas of iron, the solid solution strengthening hardness $\mathrm{Hv}^{*}{ }_{\text {sol }}$, the dislocation strengthening hardness $H v^{*}$ dis, the fine grain strengthening hardness resulting from dislocation cells $\mathrm{Hv}^{*}{ }_{c e l}$, and the fine grain strengthening hardness resulting from the large slip line spacing $\mathrm{Hv}^{*}{ }_{c s l}$. 
In a base metal with a solution-treated austenitic structure there are almost no dislocations or precipitations and therefore dislocation strengthening and precipitation strengthening can be ignored. Also, because the grain size is as large as $150 \mu \mathrm{m}$, grain strengthening barely operates. Therefore, the difference between the hardness of the base metal and the base hardness of iron $H v^{*}$ bas is thought to be the accounted for by the solid solution strengthening hardness $\mathrm{Hv}^{*}{ }_{\text {sol }}$. Of course, the solid solution strengthening hardness also exists in the specimen with a reduction in area of $50 \%$. According to Fig. 2.2 in Pickering's book. ${ }^{16)}$ the chemical components that make significant contributions to $\mathrm{Hv}^{*}{ }_{\text {sol }}$ are $\mathrm{C}, \mathrm{N}$, and Mo in Table 1. When cold-rolling is performed, the number of dislocations increases, and therefore the difference in hardness between the base metal and the first flat section in the specimen with a reduction in area of $50 \%$ is thought to be the result of the dislocation strengthening hardness $H v^{*}{ }_{d i s}$. As the indent size increases, the hardness of the specimen with a reduction in area of $50 \%$ begins to increase near $d_{c e l}$ and saturates at $10 d_{c e l}$. This tendency agrees with that of the ultra fine-grain ferrite steel in Fig. 10, suggesting that the difference in hardness between the first and second flat sections is the fine grain strengthening hardness resulting from dislocation cells, $\mathrm{Hv}^{*}{ }_{\mathrm{cel}}$. Eventually, the hardness of the specimen with a reduction in area of $50 \%$ reaches the macro-hardness at $10 l_{c s l}$. This suggests that the difference in hardness between the second and third flat sections is slip-related hardness. Thompson et al. ${ }^{17)}$ found that stress-strain curves for copper, aluminum, and brass can be well expressed by the following equation, which includes the contribution of slip lines in the Hall-Petch eq. (2).

$$
\sigma=\sigma_{0}+\left(1-\frac{\lambda}{d}\right)\left(\frac{k_{1}}{\lambda}\right)+\frac{\lambda}{d}\left(\frac{k_{2}}{d^{1 / 2}}\right)
$$

where $d$ is the crystal grain size, and $\lambda$ is the slip line length and is proportional to the slip spacing. For smaller strains, $\lambda$ approaches $d$, and consequently eq. (3) becomes the HallPetch eq. (2). For larger strains, $\lambda$ becomes smaller, resulting in an increased effect of the slip line on the strength. With these points in mind, the difference in hardness between the second and third flat sections was determined to be the fine grain strengthening hardness resulting from the large slip line spacing, $H v^{*}{ }_{c s l}$.

The relationships of the dislocation strengthening hardness $H v^{*}{ }_{d i s}$, the fine grain strengthening hardness resulting from dislocation cells $\mathrm{Hv}^{*}{ }_{c e l}$, and fine grain strengthening hardness resulting from the large slip line spacing $H v^{*}{ }_{c s l}$ to the reduction in area were obtained by using Figs. 9 and 11 and are shown in Figs. 12-14. The average values in Fig. 9 were used to obtain these hardness values. Of these three strengthening factors, the fine grain strengthening by dislocation cells is the largest, the fine grain strengthening by large slip line spacing is the second largest, and the dislocation strengthening is the smallest. The three strengthening factors are all related to dislocation and, could all be taken as dislocation strengthening. However, as described below, the strength-production mechanism in cold-rolled SUS316 (NG) steel can be clearly explained by splitting the strengthening into the three factors and discussing them individually.

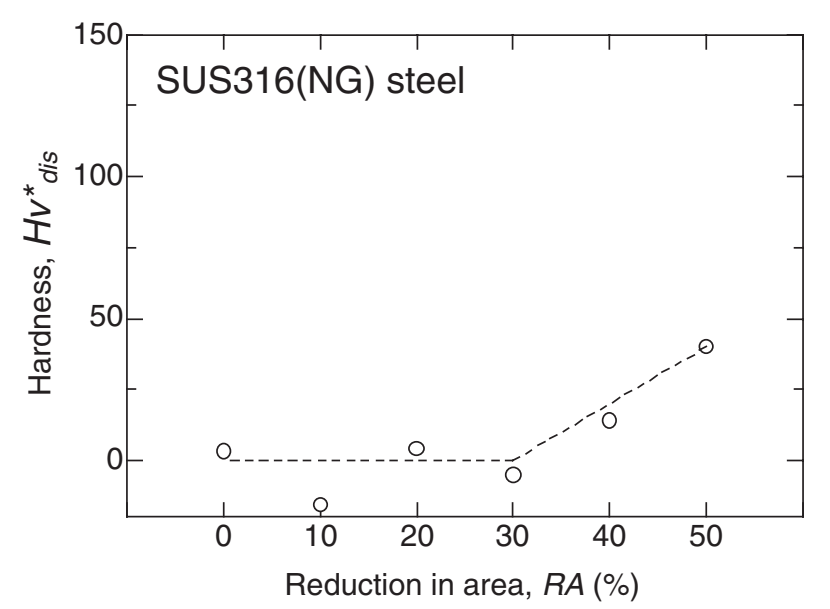

Fig. 12 Dislocation strengthing hardness, $H v^{*}{ }_{d i s}$, against reduction in area.

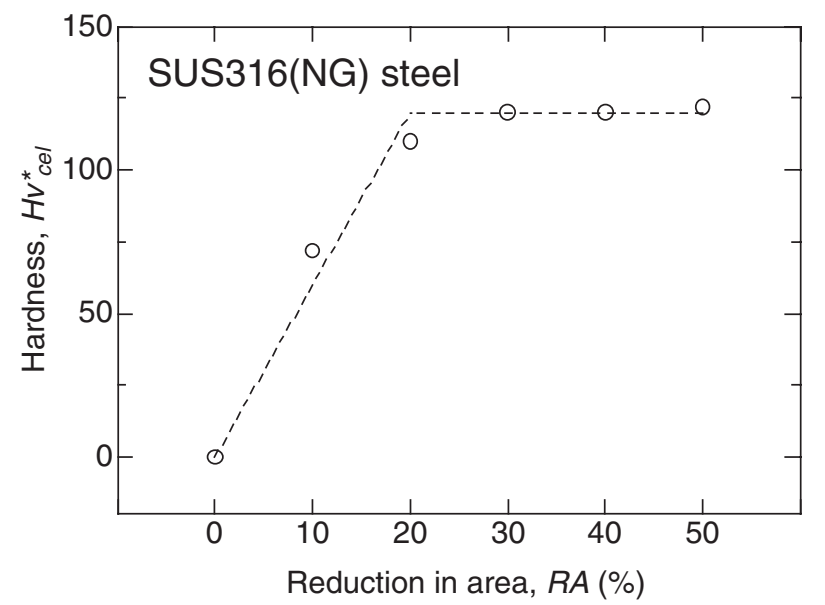

Fig. 13 Fine-grain strengthing hardness due to dislocation cell, $\mathrm{Hv}^{*}{ }_{\mathrm{cel}}$, against reduction in area.

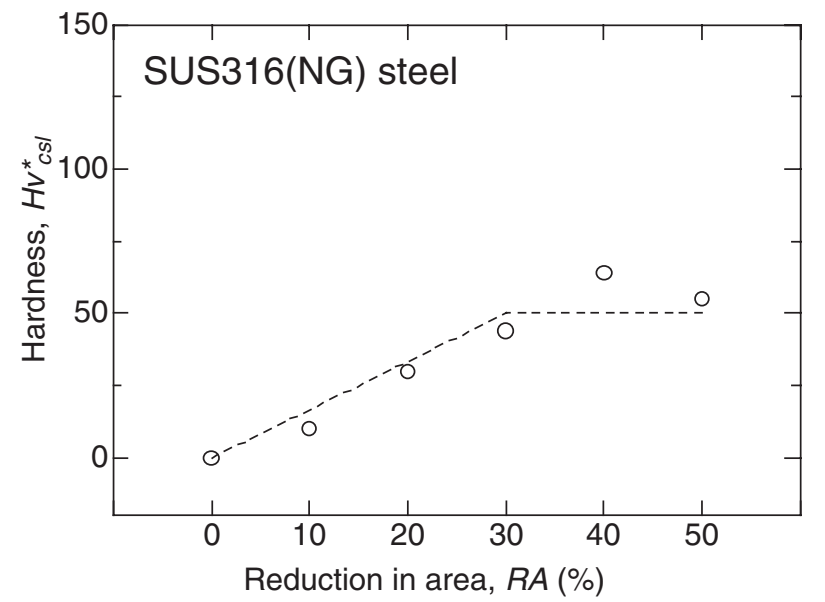

Fig. 14 Fine-grain strengthing hardness due to coarse slip spacing, $H v^{*}{ }_{c s l}$, against reduction in area.

In Fig. 12, the dislocation strengthening hardness $H v^{*}$ dis is zero at a reduction in area of less than $30 \%$ and increases for larger reductions in area. $H v^{*}$ dis was obtained by using an indent size smaller than the dislocation cell size, and can therefore be considered to be the hardness within dislocation 
cells. It follows from this that at a reduction in area of less than $30 \%$, dislocations induced by cold rolling do not exist within dislocation cells, and all of them are used for the formation of dislocation cell boundaries and slip bands. As the reduction in area increases beyond $30 \%$, dislocations begin to exist within dislocation cells, and their number increases.

As shown in Fig. 13, the fine grain strengthening hardness by dislocation cells $\mathrm{Hv}^{*}{ }_{\mathrm{cel}}$ is somewhat low at a reduction in area of $10 \%$, but saturates at nearly 120 at a reduction in area of more than $20 \%$. Fig. 6 shows that the dislocation cell size is constant at a reduction in area of more than $20 \%$. This, as well as the fact that at a reduction in area of more than $20 \%$ the dislocation density on the dislocation cell boundaries saturates and the locking parameter $k$ in the Hall-Petch equation becomes constant, can explain the constant value of $\mathrm{Hv}^{*}{ }_{\mathrm{cel}}$ for a reduction in area of more than $20 \%$. The drop in $\mathrm{Hv}^{*}{ }_{\mathrm{cel}}$ at a reduction in area of $10 \%$ is likely to be the result of the low dislocation density on the dislocation cell boundaries and the small locking parameter $k$, because the dislocation cell size at a $10 \%$ reduction in area is nearly the same as that for a reduction in area of more than $20 \%$.

In Fig. 14, as the reduction in area increases, the fine grain strengthening hardness as a result of large slip line spacing $H v^{*}{ }_{c s l}$ increases and saturates at a reduction in area of $30 \%$. According to the slip deformation model in Fig. 5, the spacing of large slips saturates at $2 \mu \mathrm{m}$ for a strain of $10 \%$, or a reduction in area of nearly $10 \%$ (see Table 1 ), and the number of fine slip lines increases in the roots of large slip lines for larger strains. This is also observable in the TEM image of the specimen rolled to a reduction in area of $30 \%$ (a true strain of $35.8 \%$ ). With the Hall-Petch equation in mind and assuming that large slip lines act as crystal grain boundaries and the locking parameter $k$ increases as the number of fine slip lines increases in the root of large slip lines, it is understandable that $H v^{*}{ }_{c s l}$ increases even at a reduction in area of more than $10 \%$. In the TEM observations, the number of slip lines increases even in the case of a reduction in area of more than $30 \%$. Therefore, $\mathrm{Hv}^{*}{ }_{c s l}$ should increase, but it actually saturates at a reduction in area of $30 \%$. However, this can be resolved by considering that fine slip lines do not contribute to increasing the locking parameter $k$ when they are formed far away from large slip lines.

The above discussion needs refinement, yet its key points can be summarized as follows:

(1) For a reduction in area of $20 \%$, the formation of dislocation cells ends, and fine grain strengthening by dislocation cells saturates (Fig. 13). (2) At a reduction in area of $30 \%$, fine grain strengthening by a combination of $2 \mu \mathrm{m}$-spaced large slip lines and fine slip lines formed in their root saturates (Fig. 14). In other words, the structure contributing to fine grain strengthening is completed at a reduction in area of $30 \%$. (3) At a reduction in area of more than $30 \%$, dislocations begin to exist within dislocation cells, and dislocation strengthening occurs (Fig. 12). Therefore, a reduction in area of $30 \%$ is a key value for the strength mechanism of cold-rolled SUS316 (NG) steel. As mentioned in the introduction, this study was motivated by the fact that SCC was observed in the work-hardened layer of shrouds and recirculation pipes. A reduction in area of $30 \%$ is also an important value for SCC.

Because SCC has been observed in the work-hardened layer of L-grade austenitic stainless steel shrouds and recirculation pipes, attention has been given to studies on the occurrence and crack growth of SCC in cold-rolled austenitic stainless steel. ${ }^{18-20)}$ Kuniya et al. ${ }^{18)}$ performed a crevice bent beam test on cold-rolled SUS304 steel under high-temperature and high-pressure water, simulating an actual usage environment. Their results show that the occurrence of TG SCC and the length of cracks formed at the same time increased rapidly for a reduction in area of more than $30 \%$. That is, the SCC sensitivity of cold-rolled steel increases at a reduction in area of more than $30 \%$. Tsubota et $a l .{ }^{20)}$ obtained nearly identical results on L-grade stainless steels SUS304L and SUS316L. Therefore, a reduction in area of $30 \%$ appears to be a key point in structure formation and the occurrence of SCC in cold-rolled L-grade SUS316 steel. Although this point remains to be clarified, one of the important factors for SCC is believed to be that at a reduction in area of $30 \%$, fine grain strengthening by dislocation cells and large slip lines saturates, and a highstrength producing structure is completed.

\section{Conclusions}

In this study, we performed ultra micro-hardness, microhardness, and Vickers hardness tests and SEM and TEM analyses on the nano-meso-macro strength of L-grade austenitic stainless steel SUS316 (NG) cold-rolled to reductions in area of 10 to $50 \%$. The results obtained are as follows:

(1) Structural parameters play an important role in the nano-meso-macro strength analysis. The SEM and TEM observations identified an austenitic grain size of $150 \mu \mathrm{m}$, slip spacings of $2 \mu \mathrm{m}$ and $20 \mathrm{~nm}$, and dislocation cell sizes of 0.15 to $0.25 \mu \mathrm{m}$ as the structural parameters of cold-rolled SUS316 (NG) steel.

(2) As a result of the ultra micro-hardness, micro-hardness, and Vickers hardness tests, the relationships between the hardness and indent size, i.e. the hardness profiles, were obtained over the nano-meso-macro regions. The hardness of the base metal was independent of the indent size and was constant at nearly 150 . The hardness of specimens cold-rolled to a reduction in area of 10 to $50 \%$ increased with increasing indent size. On the basis of the structural parameters (the dislocation cell size $d_{c e l}, 10 d_{s e l}$, which is 10 times $d_{c e l}$, and $10 l_{c s l}$, which is 10 times the $2-\mu \mathrm{m}$ large slip spacing $\left.l_{c s l}\right)$, the hardness profiles of cold-rolled specimens showed a three-step hierarchical structure. As a result, the Vickers hardness $H V$ corresponding to macro strength was split up into the base hardness $H v^{*}{ }_{\text {bas }}$ of iron, the solid solution strengthening hardness $\mathrm{Hv}^{*}$ sol, the dislocation strengthening hardness $\mathrm{Hv}^{*}$ dis, the fine grain strengthening hardness resulting from dislocation cells $H v^{*}{ }_{c e l}$, and fine grain strengthening hardness resulting from the large slip spacing $H v^{*}{ }_{c s l}$.

(3) $\mathrm{Hv}^{*}{ }_{c e l}$ and $\mathrm{Hv}^{*}{ }_{c s l}$ saturated at reductions in area of 20 and $30 \%$, respectively, and then became constant at 
values of about 120 and 50. This suggests that the formation of dislocation cells and slip bands ends at reductions in area of 20 and $30 \%$, respectively, and thus the cold-rolled structure contributing to fine grain strengthening is completed at a reduction in area of $30 \%$.

(4) $H v^{*}$ dis was zero at up to a reduction in area of $30 \%$ and then increased. This suggests that dislocations induced by cold rolling are used entirely for the formation of dislocation cells and slip bands, and that dislocations begin to exist within dislocation cells at a reduction in area of more than $30 \%$, and dislocation strengthening occurs.

\section{REFERENCES}

1) M. Kowaka: Kinzoku no fusyoku sonsyou to bousyoku gijyutu, (Agune, Tokyo, 1993) 377-404.

2) Sougo shigen energy tyousakai genshiryoku anzen hanabukai. 7th gennshiryokusetubi no kenzensei hyouka ni kannsuru syouiinnkai (2003.3.10) genshiryoku anzen hoanin.

3) K. Miyahara, S. Matsuoka, N. Nagashima and S. Mishima: Trans. Jpn. Soc. Mech. Engrs. A 61 (1995) 2321-2328.

4) K. Miyahara, N. Nagashima, S. Matsuoka and T. Ohmura: Trans. Jpn.
Soc. Mech. Engrs. A 64 (1998) 2567-2573.

5) K. Miyahara, S. Matsuoka and T. Hayashi: Metallurgical and Mater. Trans. A 32 (2001) 761-768.

6) S. Matsuoka: ISIJ 53th Shiraisi kinen kouza (2004) 51-67.

7) N. Nagashima, K. Miyahara, S. Matsuoka, K. Tsuzaki, T. Hara and T. Takahashi: Tetsu to hagane 86 (2000) 815-821.

8) H. Hirukawa and S. Matsuoka: Trans. Jpn. Soc. Mech. Engrs. A 68 (2002) 1038-1045.

9) H. Hirukawa, S. Matsuoka, Y. Furuya and K. Miyahara: Trans. Jpn. Soc. Mech. Engrs. A 68 (2002) 1473-1480.

10) S. Matsuoka: Trans. Jpn. Soc. Mech. Engrs. A 70 (2004) 1535-1541.

11) W. C. Oliver and G. M. Pharr: J. Matter. Res. 7 (1992) 1564-1583.

12) B. Jaoul: Kinzoku no sosei, (Marusen Tokyo 1969) 205.

13) M. N. Bassim and R. J. Klassen: Mater. Sci. Eng. 81 (1986) 163-167.

14) K. Miyazaki, K. Shibata and H. Fujita: Acta Met. 27 (1978) 855-862.

15) D. Tabor: The Hardness of Merals (Clarendon Press, Oxford, 1951) 34-37.

16) F. B. Pickering: Physical Metallurgy and the Design of Steels (Applied Science Publishers Ltd, London, 1978) 10-12.

17) A. W. Thompson, M. I. Baskes and W. F. Flangan: Acta Metall. 21 (1973) 1017-1028.

18) J. Kuniya, I. Masaoka and R. Sasaki: Corrosion 44 (1988) 21-28.

19) Y. Katayama, M. Tsubota and Y. Saito: Zairyou to kankyou (2004) $149-158$.

20) M. Tsubota, Y. Kanazawa and H. Inoue: 7th International Symposium on Environmental Degradation of Materials in Nuclear Power System 1 (1995) 519-527. 